\title{
Randomised controlled trial of online empathy focused intercultural communication program for Turkish local society to increase their social acceptance towards refugees
}

\author{
Arzu Çalışkan Sarı ${ }^{1}$ (1) . Özden Yalçınkaya Alkar² (i) \\ Accepted: 30 January 2022 \\ (c) The Author(s), under exclusive licence to Springer Science+Business Media, LLC, part of Springer Nature 2022
}

\begin{abstract}
The current study investigated the effectiveness of an online-based, empathy-focused intervention program that is developed for Turkish local society to increase their positive attitudes towards refugees. The sample of the four-week intervention program consisted of 52 participants that were randomly assigned to experimental $(n=26)$ and control groups $(n=26)$. Participants completed the Attitudes towards Syrians Scale in both groups before and after the intervention program. In the control group, no implementation was provided, only the individuals filled the pre-test and post-test questionnaires within the same periods as the experimental group. Participants in the experimental group also filled a sentence completion activity at the end of the program. The results of the study showed that Empathy Focused Intercultural Communication Program for Turkish Local Society showed a positive promissory approach for increasing positive attitudes towards Syrian refugees, increasing emphatic and altruistic approach. Lastly, these results, limitations, and suggestions for future research were discussed and the possible implications were shared.
\end{abstract}

Keywords Intervention for prejudice reduction $\cdot$ Attitudes towards Syrians $\cdot$ Empathy $\cdot$ Intercultural communication

\begin{abstract}
There is a concept confusion regarding the status of immigrants in the host countries and the meanings of refugee, asylum seeker and immigrant are used interchangeably. While migrants leave their country voluntarily for better living conditions, refugees lose their trust in their country and try to seek asylum in another country (UNHCR, 2002 cited in Gümüşten, 2017). While the security of the refugees in their country is in danger; immigrants may not have any security problems or even ask their country to continue to protect them. According to the Law on Foreigners and International Protection, people coming to Turkey from outside of Europe are not accepted as refugees. People from outside Europe are allowed to temporarily stay in Turkey with conditional refugee status until they are resettled in a third country. People coming from Syria with mass influx are called as "temporary protection owners" (Law No. 6458 on Foreigners and International Protection, 2013). In Turkish legal system, on the other hand, the concept of asylum seeker is not encountered (Kaya \& Eren, 2015 cited in Gümüşten, 2017). Considering the above definitions, Syrians were called as "refugees" shortly in the current article instead of using temporary protection owners in long expression.
\end{abstract}

\footnotetext{
Arzu Çalışkan Sarı

arzucaliskan26@gmail.com

Özden Yalçınkaya Alkar ozdenalkar@yahoo.com

1 Psychology Department, Çankırı Karatekin University, Ankara, Turkey

2 Ankara Yıldırım Beyazıt University, Ankara, Turkey
}

After the Syrian civil war that started in 2011, millions of people had to migrate both within and out of the country. The conflict in Syria has resulted in the internal displacement of more than six million people and the long-term mass displacement of more than five million people abroad (IOM, 2020). Turkey is one of the countries hosting the largest Syrian refugee population in the world (Çavlin, 2021). More than 3.7 million Syrian refugees live in Turkey and the government of the Republic of Turkey has granted temporary protection status to Syrians (Presidency of Migration Management, 2021). Hosting such a large number of refugees brings about some important social problems, especially in establishing harmonious relationships between the local community and refugees.

Due to the high number of Syrians and their increased visibility in the public sphere, social tensions between the local community and Syrians occasionally increase. Sharing of the limited resources, security threats, prejudices, and the perception about huge cultural differences damage the relations between the two communities (Bakioğlu et al., 2018; Ekici, 2019; Göker \& Keskin, 2015; Lemos, 2005; Navruz \& Çukurçayır, 2015). Although the Syrians feel close to the Turkish community, it is not the same case for the Turkish local community. According to the results of the comprehensive 
research conducted by Erdoğan (2020); while Syrians think that they are $57.1 \%$ similar or very similar to Turkish people in terms of culture, the rate of those who think they are not similar to Turkish people at all is only 3.6\% (Erdoğan, 2020). In addition, it has been shown in this study that Syrians feel their social distance is really low towards Turkish society and they are eager to establish close social relations. Similar studies indicate that Syrians are culturally satisfied with being in Turkey (Apak, 2014; Karasu, 2016; Kaya, 2015).

However, from the Turkish local community's point of view, the scenario is far from similar. Although there is no serious tension between the local community and Syrians, the rate of those who agree with the idea that the local community can live together with Syrians in peace is only $11.4 \%$. When the harmonization (integration) issue of Syrians is asked from Turkish society, $64.4 \%$ think that Syrians can integrate into the society very little or not at all (Erdoğan, 2020). This picture indicates that research and intervention programs should focus on the local community from now on. The social, cultural, and emotional dynamics of the Turkish host community and their sensitivities should be understood properly to create a harmonized and peaceful society. Despite the attempts to manage migration, anti-immigrant discourse and prejudice remain major concerns at the individual and societal levels. One of the explanatory factors for widespread anti-immigrant attitudes is threat perception (Croucher, 2017). Host community members worry about the economic burden of immigrants and the potential danger that they represent towards dominant host culture and the society (Çalışkan-Sarı \& Yalçınkaya-Alkar, 2018). Overall, research shows that other cultures are threats to one's own culture and this threat perception leads to prejudice and discrimination (Croucher, 2017). Integrated threat theory (ITT) developed by Stephan and Stephan brings an explanation about the sense of threat against out-groups (1993). ITT suggests that prejudice and negative attitudes towards migrants and out-groups can be explained by realistic threat, symbolic threat, negative stereotype, and intergroup anxiety. In the studies of the perception of threat towards Syrian refugees in Turkey, it is observed that there is a special emphasis on realistic threat and symbolistic threat (Karaoğlu, 2015; Keleş et al., 2016). This theory constitutes one of the bases of the current intervention study, as well.

The current migration situation and social tension in Turkey make it necessary to develop and implement some intervention programs to reduce the negative attitudes, intergroup anxiety, and prejudices of the local community towards refugees, especially towards Syrians, and to strengthen them in the context of intercultural communication. In international literature, it is seen that school-based curriculum programs are applied mostly to student samples in the context of multicultural life, breaking prejudices against refugees and preventing racism (Mansfield \& Kehoe, 1994; Vrij et al., 2003; Walker \& Crogan, 1998).

Besides school-based curriculum programs, anti-racist intervention programs are also widely used. According to literature, anti-racist intervention programs have been more beneficial and effective for children and young people than implementing a multicultural curriculum in reducing intergroup prejudices, as they include in-group discussions, activities such as role-playing, and allow them to rethink existing thoughts and attitudes (Aboud \& Levy, 2000; Dei, 1996; McGregor, 1993; Spencer, 1998). In addition, it is seen that many promising classroom programs have been developed especially for refugee children in recent years (Ingleby \& Watters, 2002; Rousseau et al., 2014; Sullivan \& Simonson, 2016). In a school-based prevention program, the socialization processes of refugee children in the host country with their peers and adults were examined in both primary and high schools. Teachers were informed about the developmental characteristics of refugee children and possible adaptation problems they may experience. In addition to providing education for teachers with multimedia-supported materials for all levels of development, education was provided to support refugee children in establishing a social bond at school (Ingleby \& Watters, 2002). All of these can be considered inspiring developments. However, considering the adaptation of the refugees in the Turkish sample, it would be much more beneficial to conduct studies, mostly for children, young people, and adults who are members of the local community. Because it can be accepted that the main problems in Turkey are increasing prejudice against Syrian refugees, social distance, and perception of cultural differences (Erdoğan, 2014). Thus, the subject of the current intervention program consists of adult local community members.

The vicarious contact method was used in another intervention program for children to reduce prejudices against Syrian refugees in Turkey. Some contact-based stories about Syrian refugees were read to Turkish primary school students and it was measured that the children in the experimental group were more willing to help outgroup members than the control group. This result was more common in children who initially had higher negative attitudes (Tercan et al., 2020). It can be considered as an efficient method that can be used when direct contact is not possible. An intervention program has also been implemented for adult local community members living in Australia to reduce prejudices against Aborigines (Hill \& Augoustinos, 2001). In the program, which was applied to 62 public services employees between the ages of 22 and 70, the stereotypes and prejudices of the participants against Aborigines were measured 3 times as just before the program, immediately after the program, and 3 months after the program ended. According to the results, there was a significant decrease in negative stereotypes and prejudices, along with an increase in knowledge about Aborigines. However, in the measurement after 3 months, there was no statistically significant difference with the baseline in prejudices and stereotypes. In other words, it was seen that the positive change in prejudices was not permanent.

In the light of the literature, a program similar to the content of anti-racist and prejudice reduction programs has been prepared and implemented for young adults in the 
current study. The rationale behind the current program is the anti-racist approach which has a stronger theoretical basis and interactive structure including role play and ingroup discussions about empathy, intercultural communication, prejudice, and discrimination (Dei, 1996). It aimed to form a mindset that enables participants to understand the characteristics of different cultures with the help of empathybased role playing and activities that can help review existing prejudices and possible discriminative behaviors.

\section{The Aim of the Study}

The present study aims to change the attitudes of Turkish local society members in a positive way towards all migrant groups, especially Syrian groups with the help of the intervention program. Individuals participating in this program understand what culture is and learn the features of culture and gain awareness regarding cultural differences. They also comprehend the importance of empathy in intercultural communication with the help of role-playing, gaining deep knowledge of ethnocentrism, prejudice, discrimination, and learning about types of discrimination.

When societies from different ethnic backgrounds are more integrated and the channels of dialogue, cooperation, and interaction are open, some groups' conscious efforts to promote hate and highlight differences will not be successful. Programs developed for local communities to increase social cohesion also strengthen the resilience of states and societies, so societies can adapt to the challenges of the twenty-first century such as forced migration. While many studies were aiming to increase the social adaptation of Syrians to the Turkish local community, as we know there has not been any intervention program for Turkish local society to increase their social acceptance of Syrians (Karasu, 2016; Yıldırımalp et al., 2017).

\section{Hypothesis}

There will be a difference between the attitudes of people participating in the empathy and intercultural communication training program for the local community aimed at increasing the social acceptance of migrants than those who do not participate in this program (control group).

\section{Method}

\section{Research Pattern}

The quantitative research method was used in this study. When the research is analyzed in terms of revealing the effects of independent variables (participation in the intervention program) on the dependent variables (attitude towards Syrians); it is an experimental model. This model was carried out by using a quasi-experimental design with pre-test and post-test comparison groups. The pre-test and post-test comparison group designs are taking measurements from the participants before and after the experimental study regarding the dependent variable (Karasar, 1999). In this model, participants are divided into two groups as experimental and control groups. While a four-week online training program was applied to the experimental group, the control group was included as a waiting list group and did not receive any training.

\section{Measures}

A demographic form, A Scale for Attitudes towards Syrians Living in Turkey, the expectation from the program, sentence completion activity on attitudes towards Syrians, and related empathy can be considered as the data collection forms. The items of the measurement tools are shown in Table 1.

\section{A Demographic Form}

A demographic form that consists of questions such as gender, age, education level, the place of birth as village, township, and province, abroad experience, and the communication experience with Syrian refugees were asked to participants to fill out.

\section{A Scale for Attitudes towards Syrians Living in Turkey}

This scale was developed to assess the attitudes of Turkish local people towards Syrians (Çalı̧̧kan-Sarı \& YalçınkayaAlkar, 2018). The scale consists of 25 items and it is Likert type. According to the factor analysis conducted with the data of this study, the three-factor structure explained 53\% of the variation. These three subscales are called attitudes about marriage relationships with Syrians, attitudes about crime relations of Syrians, and general attitudes towards Syrians about daily issues, respectively. Cronbach alpha reliability score is calculated as 0.73 . As the scores are taken from the scale increase, it means that people's attitudes towards Syrian migrants are more positive.

\section{Short Answer Form Related to Expectations for Training Program}

Before starting the training program, the participants in the intervention group were asked questions that they could give an open-ended answer about what they expect from the program and what they hope to learn. Below is a summary of the 
Table 1 Explanations for measurement tools

\begin{tabular}{|c|c|}
\hline A Demographic Form & 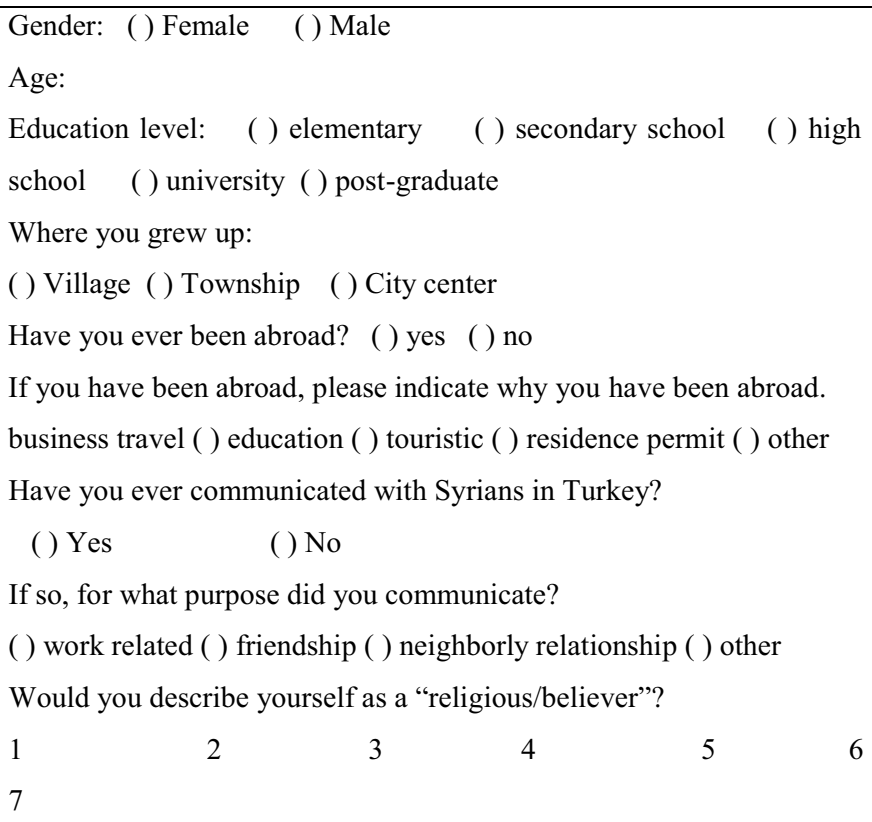 \\
\hline $\begin{array}{l}\text { A Scale for Attitudes towards Syrians } \\
\text { Living in Turkey }\end{array}$ & $\begin{array}{l}\text { 1. Migrants living in Turkey mainly consist of good people. } \\
\text { 2. I am not disturbed by the fact that migrants have free } \\
\text { access to health services } \\
\text { 3. Efforts should be made to ensure that migrants are } \\
\text { adapted to our country. } \\
\text { 4. I can become friends with a migrant. } \\
\text { 5. I am not disturbed living in the same apartment with a } \\
\text { migrant. } \\
\text { 6. I am not disturbed by the acceptance of migrants in our } \\
\text { 7. I am not disturbed working at the same workplace as a } \\
\text { migrant. } \\
\text { 8. I can be a business partner with a migrant. } \\
\text { 9. I am not disturbed by migrants getting a work permit in } \\
\text { Turkey. } \\
\text { 10. Migrants harm the country's economy. } \\
\text { 11. I am not disturbed that migrant children benefit from } \\
\text { Turkey's educational institutions. } \\
\text { 12. The attitude of migrants about cleanliness disturbs me. } \\
\text { 13. I am disturbed by the fact that migrants make too much } \\
\text { noise. }\end{array}$ \\
\hline
\end{tabular}

opinions answered by a total of 16 participants regarding the expectations from the training program: First of all, people had expectations about confronting differences with common sense and breaking people's prejudices against different cultures and identities. In addition, according to the people in the experiment group, there is a lot of negative criticism against immigrants, especially against Syrians. They would like to be informed to approach these criticisms with more effective answers.

Furthermore, they would like to understand the immigrants living in our country and to understand what kind 
Table 1 (continued)

\begin{tabular}{|c|c|}
\hline & $\begin{array}{l}\text { 15. Migrants coming to our country should be able to live in } \\
\text { city centers. } \\
\text { 16. I am not disturbed moving to a neighborhood where } \\
\text { migrants live heavily. } \\
\text { 17. I am not disturbed by the fact that migrants are allowed } \\
\text { to acquire property in our country. } \\
\text { 18. Migrants are more likely to commit crimes. } \\
\text { 19. I am not disturbed to do my shopping at the stores of } \\
\text { migrants. } \\
\text { 20. I think that migrants are often involved in theft and } \\
\text { snatching. } \\
\text { 21. I think that migrants are often involved in harassment and } \\
\text { molestation. } \\
\text { 22. I think that migrants are often involved in rape. } \\
\text { 23. I am not disturbed by my brother marrying a migrant. } \\
\text { 24. I am not disturbed marrying a migrant. } \\
\text { 25. I am not disturbed with my sister marrying migrants. }\end{array}$ \\
\hline $\begin{array}{l}\text { Short Answer Form Related to } \\
\text { Expectations for Training Program }\end{array}$ & What do you expect from the program and what do you hope to learn? \\
\hline Sentence Completion Activity Form & $\begin{array}{l}\text { 1. My views about Syrians since I attended the education program..... } \\
\text { 2. I can empathize with Syrians..... } \\
\text { 3. People belonging to different cultures.... } \\
\text { 4. If I meet a Syrian person in my life from now on..... } \\
\text { 5. My prejudice against different ethnic groups..... } \\
\text { 6. If I see a Syrian in need of help ..... } \\
\text { 7. If I had to leave my country suddenly during a conflict in my } \\
\text { country, I would feel ..... } \\
\text { 8. What advice would you give to people who have not received this } \\
\text { training (e.g. friends or family members)? }\end{array}$ \\
\hline
\end{tabular}

of difficulties they have and what they think. They are also expected to assess individually whether they have any prejudices against migrants. Besides, they would like to strengthen their communication skills with people from other cultures by increasing their ability to use empathy skills. That is, they hope to respect beliefs and thoughts in different cultures and to become able to empathize with these individuals. They would like to be a more open-minded person in approaching people from different cultures in their professional life. Some participants from the experimental group think that Turkish local society treats immigrants from the west and immigrants from the east differently in general. They hope that this issue can also be addressed in the current training. In addition, participants aimed to verify the accuracy of the information they have acquired about immigrants and their lives, to correct what they know wrong, or to learn about issues they do not know at all. Lastly, some participants aimed to break their prejudices against people who are different and to get information about people from different cultures. 


\section{Sentence Completion Activity Form}

The participants in the experimental group completed the sentences in Table 1 prepared by the researcher in the form of short answers according to their opinions at the end of the intervention program.

\section{Recruitment}

Adult local community members over the age of 18 were reached through an announcement about the program on online platforms. Being over the age of 18 and not working professionally in the field of migration are the necessary conditions for participating in the program. Apart from that, it was stated in the announcement that participants attending all sessions will be given a certificate of participation at the end of the program and a book gift card will be given to a person with a draw. In this context, 52 people in total stated that they would like to participate in the program and register by sending an e-mail to the researcher. A WhatsApp group consisting of these people was formed and randomly divided into two groups as experimental and control groups. In this context, 26 people were assigned to the experimental group and 26 people to the control group.

\section{Condition}

All of the experimental groups attended the 4-week program, but a 5-person drop out occurred in the control group.
In the pre-test and post-test applications, people were asked to create an id number (nickname) in order not to get real name information for confidentiality, and participants were asked to note this id to remember. In the control group, 2 people did not complete the final test, and the other 3 people could not participate in the sampling because the id numbers did not match. Finally, a follow-up study was carried out with the people in the experimental group, 2 months after the post-test, the participants were asked to fill in the Attitude towards Syrians Scale again, and all individuals in the experimental group answered the form.

\section{Participants}

While determining the number of participants, a g power analysis was used. According to the result, it was necessary to collect data from 52 participants with $80 \%$ power and 0.8 effect size. Recent research was completed in January 2021 with the participation of 47 people over the age of 18 . When determining the experimental and control group, a random assignment was made. The application was conducted with a total of 47 participants, 26 of whom were in the experimental group ( 21 females, 5 males) and 21 people ( 15 females -6 males) in the control group. The mean age for the experimental group was 26 while the mean age of the control group is 32. The diagram below has shown the number of participants in the intervention and control groups.

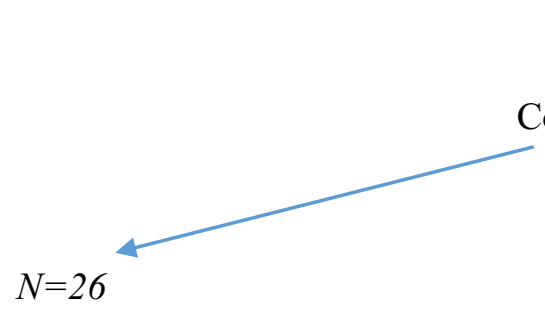

Assigned to intervention condition<smiles>C=CC</smiles>

$N=26$

Completed post-intervention measures

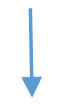

$N=26$

Completed follow up measures

$$
N=52
$$

Completed pre-intervention measures
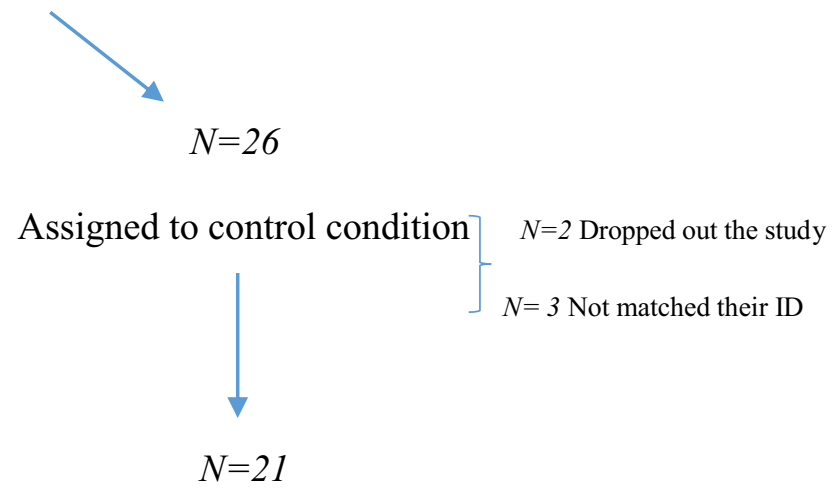

Completed post-test measures

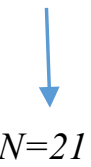

Completed all time points 


\section{Procedure}

In the experimental group, an online intervention program called "Empathy Focused Intercultural Communication Program for Turkish Local Community to Increase Their Social Acceptance towards Migrants" was conducted for 4 weeks and progressed to one hour each week. In the control group, no implementation was made, only the individuals filled the pre-test and post-test questionnaires within the same periods as the experimental group. Details of each week's implementation are as follows:

\section{Week 1:}

In the first week of the intervention, initially participants got to know each other and the researcher. Then, the researcher informed the group about the content of the training program. The purpose, duration, and rules of the program were shared. After that, the researcher collected the expectations from the program as written and implemented the pre-test. Finally, the researcher informed the group about the what is the culture and culture's components.

Week 2:

The second week of the program started with a warmup activity whose name is now and here. Then, the researcher informed the group about empathy in the context of intercultural communication.

Week 3:

In the third week, after the researcher repeated the content from the previous week, she informed the group about ethnocentrism, prejudice, and discrimination. Then, the researcher made some explanations and exercises about the types of prejudice and discrimination.

Week 4:

In the last week, the main purpose was to increase the sensitivity of the group regarding cultural differences. In this way, after the researcher explained Bennet's Intercultural Sensitivity Development Model, she had the individuals in the group talk about which step of the model they were in. Another purpose of the week was to increase the awareness of the group on incomplete or misinformation about Syrians that can cause intergroup anxiety. Lastly, participants were instructed to complete a post-intervention test (the scale of attitudes towards Syrians) and sentence completion activity about the program.

\section{Statistical Analysis}

2 (intervention vs. control) $\times 2$ (Time 1 vs. 2 ) mixed design ANOVA was used to determine whether there was a significant difference between the pre-test and post-test scores of the experimental and control groups. Follow-up measurement was also taken for the experimental group and the mean score for it was reported. SPSS 20 package program was used for statistical analysis The data obtained as a result of the research were evaluated at a 0.05 significance level.

\section{Results}

\section{Descriptive Statistics}

Summary statistics were calculated for each interval and ratio variable. Frequencies and percentages were calculated for each nominal variable. Frequencies and percentages are presented in Table 2.

The average age of participants was $27.13(S D=4.03$, $\operatorname{Min}=18.00, \operatorname{Max}=36.00)$. The most frequently observed category of the group was experimental $(n=26,55 \%)$. Females constituted the majority of the participants $(n=36$, $77 \%)$. Most of the participants were university graduates $(n=35,74 \%)$. The most frequently observed category of being abroad before consisted of no answer $(n=26,55 \%)$. In addition, the most frequently observed category of social contact experience with the Syrians in Turkey consisted of a yes answer ( $n=29,62 \%)$. Finally, the most frequently observed category of the place where participants grew up was a city center $(n=41,87 \%)$.

Table 2 Demographic and attitudes towards syrians related characteristics of the sample

\begin{tabular}{|c|c|c|c|c|}
\hline \multirow[t]{2}{*}{ Variable } & \multicolumn{2}{|c|}{$\begin{array}{l}\text { Experimental } \\
(n=26)\end{array}$} & \multicolumn{2}{|c|}{$\begin{array}{l}\text { Control } \\
(n=21)\end{array}$} \\
\hline & $N$ & $\%$ & $n$ & $\%$ \\
\hline \multicolumn{5}{|l|}{ Gender } \\
\hline Female & 21 & 80.8 & 15 & 71.4 \\
\hline Male & 5 & 19.2 & 6 & 28.6 \\
\hline \multicolumn{5}{|l|}{ Education Level } \\
\hline Secondary school & 0 & 0.0 & 1 & 4.8 \\
\hline High school & 1 & 3.8 & 4 & 19.0 \\
\hline University & 21 & 80.8 & 14 & 66.7 \\
\hline Master & 4 & 15.4 & 2 & 9.5 \\
\hline \multicolumn{5}{|l|}{ Abroad Experience } \\
\hline No & 16 & 61.5 & 10 & 47.6 \\
\hline Yes & 10 & 38.5 & 11 & 52.4 \\
\hline \multicolumn{5}{|c|}{ Social Contact Experience with Syrians } \\
\hline No & 9 & 34.6 & 9 & 42.9 \\
\hline Yes & 17 & 65.4 & 12 & 57.1 \\
\hline \multicolumn{5}{|c|}{ The place where you grew up } \\
\hline Township & 4 & 15.4 & 2 & 9.5 \\
\hline City center & 22 & 84.6 & 19 & 90.5 \\
\hline
\end{tabular}

Note. Due to rounding errors, percentages may not equal $100 \%$ 
Table 3 Summary statistics table for pre-test, post-test, and follow up scores of attitudes towards syrians

\begin{tabular}{|c|c|c|c|c|c|c|c|c|}
\hline \multirow[b]{2}{*}{ Variable } & \multicolumn{4}{|c|}{$\begin{array}{l}\text { Experimental } \\
(n=26)\end{array}$} & \multicolumn{4}{|c|}{$\begin{array}{l}\text { Control } \\
(n=21)\end{array}$} \\
\hline & $M$ & $S D$ & Min & Max & $M$ & $S D$ & Min & $\operatorname{Max}$ \\
\hline Pre-test & 78.81 & 24.37 & 41.00 & 125.00 & 69.71 & 22.10 & 32.00 & 117.00 \\
\hline Post-test & 94.23 & 22.93 & 28.00 & 123.00 & 66.57 & 22.85 & 32.00 & 115.00 \\
\hline Follow up & 95.85 & 20.85 & 48.00 & 123.00 & & & & \\
\hline
\end{tabular}

Impact of the Empathy Based Intervention Program

Summary statistics were calculated for pre-test, post-test, and follow-up scores of attitudes towards Syrians. The summary statistics can be found in Table 3 .

For the experimental group, the observations for pretest had an average of $78.81(S D=24.37$, Min $=41.00$, Max $=125.00$ ). The observations for post-test had an average of $94.23(S D=22.93, \operatorname{Min}=28.00, \operatorname{Max}=123.00)$. The observations for follow up had an average of $95.85(S D=20.85$, $\operatorname{Min}=48.00$, $\operatorname{Max}=123.00$ ) for the experimental group.

For the control group, the observations for pre-test had an average of $69.71(S D=22.10, \operatorname{Min}=32.00, \operatorname{Max}=117.00)$. The observations for post-test had an average of 66.57 $(S D=22.85, \operatorname{Min}=32.00, \operatorname{Max}=115.00)$.

\section{Mixed Design ANOVA Results}

A mixed-design analysis of variance (ANOVA) with one within-subjects factor and one between-subjects factor was conducted to determine whether significant differences exist between pre-test and post-test scores of the levels of grouping. Table 4 presents the ANOVA results.

The main effect for the group was significant, $F(1$, $45)=8.44, p=0.006$, indicating that there were significant differences in pre-test and post-test between the levels of grouping. The experimental group's total pre-test and posttest scores are significantly higher than the total pre-test and post-test scores of the control group.

The main effect for the within-subjects factor was significant, $F(1,45)=6.20, p=0.017$, indicating there were significant differences between the values of pre-test and post-test. The total post-test scores of the experiment group for positive attitudes towards Syrians were higher than the pre-test scores of the experiment group. However, the total post-test scores of the control group were lower than the total pre-test scores.

The interaction effect between the within-subjects factor and group (Condition $\mathrm{x}$ Time) was significant, $F$ (1, $45)=14.17, p<0.001$, indicating that the relationship between pre-test and post-test differed significantly between the levels of grouping. The significance of the interaction effect indicates that the experimental-group participants' training was effective at increasing positive attitudes towards Syrians. In other words, attitudes towards Syrian refugees changed between the pre-test and post-test in the intervention condition but did not change between pre-test and posttest in the control condition. The variation in mean attitudes towards Syrians scores for the pre-test and post-test scores is shown in Fig. 1.

\section{The Results of Sentence Completion Activity}

At the end of the 4-week online training program, a sentence completion activity was applied to the participants to give open-ended answers. 20 participants completed the sentence completion activity. Below are the frequencies and percentages of 8 sentence completion activities classified according to similar answers: (See Table 5).

$I^{\text {st }}$ Sentence: The sentence that started with the expression that "My views towards Syrians....." was completed with the statement that $15(75 \%)$ of the participants changed positively, while $2(10 \%)$ people did not change their views. 1 person (5\%) did not already have negative thoughts while $2(\% 10)$ participants also stated that they partially changed.

$2^{\text {nd }}$ sentence: In the sentence that begins with the statement that "...I can empathize with Syrians", 18 (90\%) of the participants used a positive expression as I think

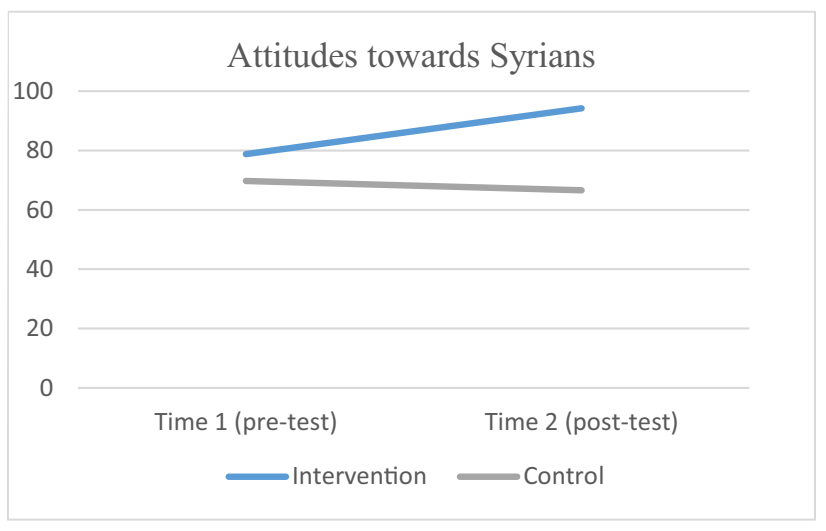

Fig. 1 Variation in intervention and control groups mean positive attitude towards Syrians scores 
Table 4 Mixed design ANOVA results

\begin{tabular}{llrrrrr}
\hline Source of Variance & $d f$ & \multicolumn{1}{c}{$S S$} & \multicolumn{1}{c}{$M S$} & \multicolumn{1}{c}{$F$} & $\eta_{\mathrm{p}}{ }^{2}$ \\
\hline Between-Participants & & & & & & \\
Group (Experimental/Control) & 1 & 7845.93 & 7845.93 & 8.44 & 0.006 & 0.16 \\
Residuals & 45 & 41842.62 & 929.84 & & & \\
Within Participants (pre-test/post-test) & 1 & 875.95 & 875.95 & 6.20 & 0.017 & 0.12 \\
Intercept (Group x Measure) & 1 & 2002.16 & 2002.16 & 14.17 & $<0.001$ & 0.24 \\
Residuals & 45 & 6357.46 & 141.28 & & & \\
\hline
\end{tabular}

or felt, while $2(10 \%)$ stated that I think but I know it is not enough.

$3^{\text {rd }}$ sentence: In the sentence that begins with the statement that "People from different cultures....", While 4 people (20\%) completed this sentence as should not be exposed to negative discrimination and prejudice, 8 people (40\%) completed it as diversity. While 2 people $(10 \%)$ completed the sentence saying they are no different, 2 people (10\%) completed the sentence as we should respect. 4 people (20\%) completed it with sentences that can manage to live together.

$4^{\text {th }}$ sentence: The sentence that begins with the phrase that "If I meet a Syrian person in my future life ...." was completed by 8 participants $(40 \%)$ as I would be careful enough to behave understandingly. While 6 people (30\%) said that I would not think of anything positive or negative, 2 people (10\%) answered that $I$ would behave the same way I behave a Turkish person. One participant (5\%) replied that I would smile, and 1 person (5\%) said I would ask more careful questions (non-traumatic). One participant (5\%) answered that $I$ take care to help whenever he/she needs help. Finally, one participant (5\%) completed the sentence saying, $I$ can live in the same environment.

$5^{\text {th }}$ sentence: The sentence that started as "My bias against different ethnic groups ...." was completed by 5 participants $(25 \%)$ as are not while 8 people $(40 \%)$ completed it as is decreasing. 4 people $(20 \%)$ answered that I am trying to overcome this from time to time, and 2 people (10\%) said that it was very few before the training. 1 participant $(5 \%)$ completed the sentence as can be, but it depends on the ethnic group.

$\boldsymbol{6}^{\text {th }}$ sentence: While 17 people $(85 \%)$ complete the sentence that begins with "I see a Syrian in need of help...." as I can help, 2 people (10\%) inform someone who can help (such as social aid organizations, police). 1 participant (5\%) completed the sentence as I behave as I do he/she is a Turk in need.

$7^{\text {th }}$ sentence: The sentence saying that "If I had to leave my country suddenly in a conflict, I would feel ... " was completed by 11 participants (60\%) as I would feel bad and anxious. 5 people (25\%) completed it as frightened and desperate. One person (5\%) completed the sentence saying that I would feel lonely and weak while 2 participants $(10 \%)$ would feel bad, but I would not leave my country, even if I was going to die.

$\boldsymbol{8}^{\text {th }}$ sentence: Finally, to the question of "What advice can you give to people who have not received this training (for example, friends or family members)", 9 people (45\%) advised them to empathize with immigrants, and 2 participants (10\%) to attend similar training. 5 participants (25\%) answered that I would like to explain their involuntary or deliberate prejudices and discrimination to them through examples. 4 people (20\%) replied that $I$ recommend that they evaluate their existing judgments to gain awareness.

\section{Proof of Hypothesis}

According to the above results and observations, the hypothesis has been proved.

\section{Discussion}

A recent study has investigated the effectiveness of onlinebased, empathy-focused intercultural communication programs for young adults. Within the framework of the hypothesis, the results of the current intervention study demonstrated that participation in an online-based, empathyfocused intercultural communication program gave rise to an increase in Turkish local society's positive attitudes towards Syrian refugees and their emphatic and altruistic approach.

In international literature, similar results were observed when intervention programs aimed at reducing prejudice against refugees were examined (Turner \& Brown, 2008; Vassilopoulos et al., 2020). However, most of the studies were conducted with student samples in the classroom environment. For example, according to the results of the intervention program conducted with the participation of 106 young adolescent students in Greece, the attitudes of the students in the intervention program were found to be more positive towards refugees compared to the control group, while their general empathy capacities were also increased. 
Table 5 Summary statistics for sentence completion activity

\begin{tabular}{|c|c|c|}
\hline Answer Sentences & $\mathrm{N}=20$ & $\%$ \\
\hline \multicolumn{3}{|l|}{$1^{\text {st }}$ sentence: "My views towards Syrians......" } \\
\hline changed positively & 15 & 75 \\
\hline did not change their views & 2 & 10 \\
\hline did not already have negative thoughts & 1 & 5 \\
\hline partially changed & 2 & 10 \\
\hline \multicolumn{3}{|l|}{$2^{\text {nd }}$ sentence: "....I can empathize with Syrians" } \\
\hline I think or felt & 18 & 90 \\
\hline I think but I know it is not enough & 2 & 10 \\
\hline \multicolumn{3}{|l|}{$3^{\text {rd }}$ sentence: "People from different cultures...." } \\
\hline should not be exposed to negative discrimination and prejudice & 4 & 20 \\
\hline are diversity & 8 & 40 \\
\hline can manage to live together & 4 & 20 \\
\hline they are not different & 2 & 10 \\
\hline we should respect & 2 & 10 \\
\hline \multicolumn{3}{|l|}{$4^{\text {th }}$ sentence: "If I meet a Syrian person in my future life ...." } \\
\hline I would be careful enough to behave understandingly & 8 & 40 \\
\hline I would not think of anything positive or negative & 6 & 30 \\
\hline I would behave the same way I behave a Turkish person & 2 & 10 \\
\hline I would smile & 1 & 5 \\
\hline I would ask more careful questions (non-traumatic) & 1 & 5 \\
\hline I take care to help whenever he/she needs help & 1 & 5 \\
\hline I can live in the same environment & 1 & 5 \\
\hline \multicolumn{3}{|l|}{$5^{\text {th }}$ sentence: "My bias against different ethnic groups ...." } \\
\hline are not & 5 & 25 \\
\hline is decreasing & 8 & 40 \\
\hline I am trying to overcome this from time to time & 4 & 20 \\
\hline it was very few before the training & 2 & 10 \\
\hline can be, but it depends on the ethnic group & 1 & 5 \\
\hline \multicolumn{3}{|l|}{$6^{\text {th }}$ sentence: "I see a Syrian in need of help...." } \\
\hline I can help & 17 & 85 \\
\hline inform someone who can help (such as social aid organizations, police) & 2 & 10 \\
\hline I behave as I do he/she is a Turk in need & 1 & 5 \\
\hline \multicolumn{3}{|l|}{$7^{\text {th }}$ sentence: "If I had to leave my country suddenly in a conflict, I would... " } \\
\hline feel bad and anxious & 12 & 60 \\
\hline feel frightened and desperate & 5 & 25 \\
\hline feel lonely and weak & 1 & 5 \\
\hline feel bad, but I would not leave my country, even if I was going to die & 2 & 10 \\
\hline \multicolumn{3}{|l|}{ " $8^{\text {th }}$ sentence: What advice can you give to people who have not received this training (for example, friends or family members)" } \\
\hline to empathize with immigrants & 9 & 45 \\
\hline I would like to explain their involuntary or deliberate prejudices and discrimination to them through examples & 5 & 25 \\
\hline I recommend that they evaluate their existing judgments in order to gain awareness & 4 & 20 \\
\hline to attend similar training & 2 & 10 \\
\hline
\end{tabular}

In addition, the tolerance of the students in the intervention group increased and they showed less xenophobia. The popular and most preferred approach in intervention programs relating to increasing positive attitudes towards different ethnic groups is based on recognizing the racism that exists in individuals and in the society they live in, and raising the level of awareness required to combat this racism (Dei, 1996; Short \& Carrington, 1996; Walker, 1989). 
Besides, some intervention programs aiming to increase positive attitudes towards different ethnic groups are implemented as curriculum programs that emphasize multiculturalism (Mansfield \& Kehoe, 1994). Multicultural curriculum programs are based on the assumption that prejudice stems from ignorance. Therefore, informing the participants about the lifestyle and culture of minority groups reduces prejudice and changes participants' behavior towards minority groups (Aydin, 2013). To summarize, education initiatives with the help of multicultural curriculum programs foster positive relationships by challenging stereotypes and myths about the outgroups. The current intervention program continued the lessons interactively with the participants, using the themes from both two approaches to alleviate negative attitudes towards refugees. For example, ethnocentrism and prejudices that can cause discrimination and racism were frequently emphasized and the participants were asked to give examples of the types of discrimination they see in their lives and environments, as well.

A similar intervention program for adolescent students in Greece was carried out with primary school children in England (Turner \& Brown, 2008). 87 primary school students aged between 9 and 11 participated in the study, aiming to increase positive attitudes towards refugees with a multicultural curriculum and an anti-racist intervention program in the school environment. At the beginning and the end of the program, students' attitudes towards refugees, their empathy levels, and their preferred acculturation strategies were measured. The attitudes of the students at the end of the program were turned positive at the end of the program, but when the attitudes were measured again after 7 weeks, it was seen that the same result as the pre-test was obtained. In other words, it has been observed that the positive effect of the intervention program on attitudes is not permanent. When the acculturation model preferred by the students was examined, it was observed that the students in the experimental group adopted less assimilation and more integration models in the post-test, while the control group remained constant in the assimilation acculturation model both in the pre-test and the post-test. There was no difference in the empathy levels of the students before and after the program (Turner \& Brown, 2008).

An interesting intervention program aimed to increase advocacy for diversity, equality, and social inclusion was also conducted with the participation of faculty members from different universities in the United States (Chen et al., 2020). The content of the intervention program which was carried out with 29 faculty members consisted of recognizing and defining ethnic differences, equality, and social inclusion. The intervention program included a 3-day workshop and three journal clubs. Participants were followed for 1 year and self and collective efficacy measurements were taken from time to time to define and examine ethnic differences, equality, and inclusion. According to the results of the research, it was seen that there was a significant difference between pre-test and 5 months after the pre-test measurements in the self-efficacy and collective efficacy levels. After the intervention program was implemented, people's self-and collective competencies to recognize equality, diversity, and social inclusion increased significantly. In the measurements after 1 year, it was observed that selfefficacy was considerably higher than the pre-test measurements (Chen et al., 2020). To sum up, this intervention study that has been carried out recently with an adult sample has also effective and important results that emphasize ethnic diversity and equality.

As we know, there has not been any intervention program designed to change the local society's attitudes toward the Syrian refugees positively in Turkey. It is thought that the current study will make a great contribution to the literature in this sense. In addition, the current study is innovative in terms of applying for the empathy-focused intercultural communication program in adult samples and online. Before the intervention program started, expectations about the training were collected from the participants in writing. In general, it has been revealed that there is an expectation that there will be an education aimed at reducing prejudice against different cultures and identities. In addition, some participants have expectations to get information about immigrants and their lives and to correct misunderstood facts about Syrians. In this context, it can be said that study is carried out with a group that is open to learning and has a high awareness level. Despite this, a significant increase in the positive attitudes of the experimental group towards Syrians compared to pretest scores is reported. That is, a ceiling effect on positive attitudes is not observed. This indicates that the content of the program is very strong in changing attitudes towards Syrians.

The current intervention program not only led to an increase in people's positive attitudes but also an overall increase in participants' empathy levels and altruistic behavior towards Syrians. This result is reached through the sentence completion task applied at the end of the program. In the sentence completion task which with the participation of 20 people from the experimental group, the general subject of the sentence completion task is about the increase in their empathy levels. In addition, displaying less prejudiced and more benevolent behavior towards Syrians in their daily life after the program is one of the topics that are frequently written in sentence completion tasks. Based on these results, the intervention program not only changed the attitudes of the local community towards Syrian refugees positively but also increased their empathic approach and increased their sense of humanitarian approach. The importance of social and cognitive phenomena in reducing prejudices cannot be underestimated (Aboud, 2008; Rutland et al., 2010). There 
are studies with successful results that focus on changing the intergroup attitudes of children, adolescents, and adults by using social, cognitive, and moral skills such as social categorization, perspective-taking, empathy, which are also used in the current study (Levy et al., 2016).

In line with the findings of the recent study, suggestions that can shed light on future studies and help psychologists, social workers, psychological counselors, migration experts, migration managers, and other experts working in international organizations or non-governmental organizations can be reported. First of all, migration is a very challenging field of study in terms of managing intergroup relations and developing positive relations. In this context; the psychological and sociological dimensions of migration should never be overlooked and the perceptions and reactions of the local community should always be taken into account and evaluated. If the people from different groups make feel connected with certain universal human values and the perception that there are more similarities than differences, a more positive picture will emerge in the context of intergroup relations. Of course, it is a reality that there are some cultural differences between Turkish local society and Syrians and these differences should be known in order not to cause interpersonal misunderstanding and conflict. However, it should be emphasized that differences are diversity and there are many similarities between people from different groups.

In addition, making over-generalizations about the people from different nationalities just because of group membership also strengthens the prejudices. It is important to avoid generalizations and emphasize that people have their unique behavioral patterns and these patterns make them "special" or "unique" in the world they live in. An approach that overemphasizes the differences between groups and ignores individual differences will create difficulties in finding peace and coexistence. Perceiving the refugees not as individuals but as groups such as Syrians or Afghans prevents people from seeing the unique characteristics of the individuals. In future intervention programs, it will be beneficial to prepare the module contents in a way that prevents over-generalizations about different groups.

Apart from over-generalization about different groups, local people have some anxieties about Syrians because of the threat that these groups may change the demographic structure and create an economic burden for the host country. It is a very reasonable situation to have some anxieties about different groups due to economic and security reasons (Ulukütük, 2017). One of the ways to reduce these intergroup anxieties is to provide accurate information quickly and before the rumors about these groups are well penetrated. People who are constantly exposed to false information about a group remember them correctly over time (Horowitz, 2001). For this reason, it is necessary to be transparent for the authorities that manage the migration policies to prevent information pollution, especially about Syrians, by providing accurate information for the local community periodically.

\section{Limitations and Recommendations for Future Research}

Online Empathy Focused Intercultural Communication Program for Turkish Local Society had promising results for decreasing negative attitudes towards Syrian refugees and increasing emphatic approach. However, further studies should be carried out to assess the efficacy of this program in larger and different age groups with different socioeconomic statuses. Since the study's sample consists of young adults between the ages of 18-36 and mostly university graduates and females, there may be some problems in terms of generalizability. However, since the intervention study is online and requires internet literacy and continuity (4 weeks), it is an expected result to attract the attention of young and female groups with a high level of education.

In addition, it was not possible to conduct this intervention study face-to-face during the Covid-19 outbreak, where there was a complete obstruction from time to time and schools were mostly closed in Turkey. After the Coronavirus outbreak, this program can also be applied face to face. In this way, some negative effects of online programs like possible problems with the internet or technology use can be reduced and more interaction with the participants can be achieved. Furthermore, when the announcements of such intervention programs are made through social media platforms, it is not possible to reach individuals who do not have internet access or who do not have computer/internet literacy. This decreases the generalizability of the study. In future studies, the comparison of the effects of both online and face-to-face programs for changing attitudes towards refugees will make a great contribution to the literature. In this way, the effect of methodological differences in attitude change will also be recognized.

Lastly, in the present study, no intervention was implemented in the control group and the group was considered as a waiting group. Only pre-test and post-test were performed for the control group. However, in future studies, two types of control groups can be used. One of them will be the waiting group and no program will be implemented, while the other control group can be trained on any subject independent from empathy, prejudice, and discrimination themes. Comparing these three groups in terms of attitudes towards migrants can provide stronger data. 


\section{Conclusion}

To conclude, despite the limitations of the current intervention program, it has had a positive impact on attitudes towards refugees in a limited time and has led to positive changes in local people's empathy and intercultural communication. In the countries like Turkey where the ratios of migrants are high, it is essential to implement intervention programs for the local community members that will strengthen empathy and intercultural communication. In most countries, such programs have been implemented in secondary and high schools. However, it is necessary to increase the number of programs aimed at reducing prejudices towards migrant groups in the adult sample, as well.

Declarations The datasets generated during and/or analysed during the current study are available in the [intervention program data set_Arzu ÇALIŞKAN SARI] repository, [https://drive.google.com/drive/folde rs/1SKL4DOizwC7hnLrUc8Xo35zsLUc1pZIs].

Ethical Approval Ethical approval has taken from Ankara Yıldırım Beyazıt University on 29th May 2019.

Informed Consent Informed consent was obtained from all individual participants included in the study.

Conflict of Interest There is no conflict of interest in the current study.

\section{References}

Aboud, F. E. (2008). A social-cognitive developmental theory of prejudice. In S. M. Quintana \& C. McKown (Eds.), Handbook of race, racism, and the developing child (pp. 55-71). Wiley. https://doi.org/10.1002/9781118269930.ch4

Aboud, F. E., \& Levy, S. R. (2000). Interventions to reduce prejudice and discrimination in children and adolescents. In S. Oskamp (Ed.), Reducing prejudice and discrimination (pp. 269-293). Lawrence Erlbaum Associates Publisher.

Apak, H. (2014). Suriyeli göçmenlerin kente uyumları: Mardin örneği. Mukaddime, 5(2), 53-70.

Aydin, H. (2013). A literature-based approaches on multicultural education. The Anthropologist, 16(1-2), 31-44. https://doi.org/ 10.1080/09720073.2013.11891333

Bakioğlu, A., Artar, F., \& İzmir, H. (2018). Ankara'daki Suriyelilerin mültecilik deneyimleri: göç, gündelik yaşam, geçim deneyimleri ve sosyal dişlanma. Sociological Association Publications, Publication No: 25.

Çalışkan-Sarı, A., \& Yalçınkaya-Alkar, Ö. (2018). The attitudes towards Syrians living in Turkey: A scale development. The Journal of Migration Studies, 4(2), 10-36.

Çavlin, A. (2021). Syrian refugees in Turkey: A demographic profile and linked social challenges. Routledge.

Chen, J. A., Tutwiler, M. S., \& Jackson, J. F. L. (2020). Mixedreality simulations to build capacity for advocating for diversity, equity, and inclusion in the geosciences. Journal of Diversity in Higher Education. https://doi.org/10.1037/dhe0000190

Croucher, S. M. (2017). "Integrated threat theory," in Intergroup Communication Encyclopaedia, eds J. Harwood and H. Giles. Retrieved January 10, 2021 from: http://communication.oxfor dre.com/view/10.1093/acrefore/9780190228613.001.0001/acref ore-9780190228613-e-490

Dei, G. J. S. (1996). Anti-racism education: theory and practice. Fernwood.

Ekici, H. (2019). Türk toplumunda Suriyelilere yönelik algılanan tehditler ve çözüm önerileri. Sosyal Politika Çalışmaları Dergisi, 44, 695-730.

Erdoğan, M. M. (2014). Türkiye'deki Suriyeliler: Toplumsal Katılım ve Uyum (p. 3). Hacettepe University Migration and Politics Research Centre.

Erdoğan, M. M. (2020). Suriyeliler barometresi 2019, Suriyelilerle uyum içinde yaşamın çerçevesi. Orion Kitabevi.

Göker, G., \& Keskin, S. (2015). Haber medyası ve mülteciler: Suriyeli mültecilerin Türk yazılı basınındaki temsili [News media and refugees: Representation of Syrian refugees in Turkish press]. Iletişim Kuram ve Araştırma Dergisi, 41, 229-256.

Gümüşten, D. (2017). Mülteci çocukların eğitimi ve uyumlarına yönelik yapılan müdahale programları üzerine bir derleme. Nesne Psikoloji Dergisi, 5(10), 247-264.

Hill, M. E., \& Augoustinos, M. (2001). Stereotype change and prejudice reduction: Short- and long-term evaluation of a crosscultural awareness program. Journal of Community and Applied Social Psychology, 11, 243-262.

Horowitz, D. (2001). The deadly ethnic riot. University of California Press.

Ingleby, D., \& Watters, C. (2002). Refugee children at school: Good practices in mental health and social care. Education and Health, 20(3), 43-45.

IOM (2020). World Migration Report 2020. Switzerland. Retrieved July 17, 2021 from https://publications.iom.int/system/files/pdf/ wmr_2020.pdf

Karaoğlu, E. (2015). The Role of Social Dominance Orientatiton, Empathy and Perceived Threat in Predicting Prejudice of Turkish Citizens Towards Syrian Immigrants. (Master Thesis). METU Graduate School of Social Sciences, Ankara.

Karasar, N. (1999). Bilimsel araştırma yöntemi. Nobel Yayın Dağıtım

Karasu, M. A. (2016). Şanlıurfa'da yaşayan Suriyeli sı̆̆ınmacıların kentle uyum sorunu. Süleyman Demirel Üniversitesi İktisadi ve İdari Bilimler Fakültesi Dergisi, 21(3), 995-1014.

Kaya, M. (2015). Komşuda misafirlik: Suriyeli sı̆̆ınmacılarca kurulmuş mülteci derneklerinin perspektifinden Türkiye'de yaşamak. International Journal of Social Science, 39, 263-279.

Kaya, İ. ve Eren, E. Y. (2015). Türkiye'deki Suriyelilerin Hukuki Durumu. Report no: 50. İstanbul: SETA Publication. Retrieved March 10, 2020 from http://file.setav.org/Files/Pdf/2015123013 4459_turkiyedeki-suriyelilerinhukukidurumu-pdf.pdf

Keleş, S. Ç., Aral, T., Yıldırım, M., Kurtoğlu, E., \& Sunata, U. (2016). Attitudes of Turkish youth toward Syrian refugees in respect to youths' gender, income, education, and city: a scale development study. Turkish Migration 2016 Selected Papers, 155-163.

Law no. 6458 on Foreigners and International Protection. (2013). T.C. Government Legislation, 28615, 11 April 2013.

Lemos, G. (2005). Challenging and changing racist attitudes and behaviour in young people. JRF. Retrieved July 14, 2021 from https://www.jrf.org.uk/report/challenging-and-changing-racistattitudes-and-behaviour-young-people.

Levy, S. R., Lytle, A., Shin, J. E., \& Hughes, J. M. (2016). Understanding and reducing racial and ethnic prejudice among children and adolescents. In D. Nelson (Ed.), Handbook of prejudice, stereotyping, and discrimination (pp. 455-484). Psychology Press.

Mansfield, E., \& Kehoe, J. (1994). A critical examination of anti-racist education. Canadian Journal of Education, 19(4), 418-430. https://doi.org/10.2307/1495340

McGregor, J. (1993). Effectiveness of role-playing anti-racist teaching in reducing student prejudice. Journal of Educational Research, $86(4), 215-226$. 
Navruz, M., \& Çukurçayır, M. A. (2015). Factors affecting changes in perceptions of Turkish people towards Syrian refugees. International Journal of Social Sciences, 4, 75-85.

Presidency of Migration Management (2021). Temporary Protection Statistics. Turkey. Retrieved December 10, 2021 from https://en. goc.gov.tr/temporary-protection 27

Rousseau, C., Beauregard, C., Daignault, K., Petrakos, H., Thombs, B. D., Steele, R., ... Hetcham, L. (2014). A cluster randomizedcontrolled trial of a classroom-based drama workshop program to improve mental health outcomes among immigrant and refugee youth in special classes. PloS One, 9(8), 1-9. i: https://doi.org/10. 20472/SS2015.4.4.006

Rutland, A., Killen, M., \& Abrams, D. (2010). A new social-cognitive developmental perspective on prejudice: The interplay between morality and group identity. Perspectives on Psychological Science, 5(3), 279-291. https://doi.org/10.1177/1745691610369468

Short, G., \& Carrington, B. (1996). Anti-racist education, multiculturalism, and the new racism. Educational Review, 48, 65-77.

Spencer, M. S. (1998). Reducing racism in schools: Moving beyond the rhetoric. Social Work in Education, 20, 25-36.

Stephan, W. G., \& Stephan, C. W. (1993). Cognition and affect in stereotyping: Parallel interactive networks. In D. M. Mackie \& D. L. Hamilton (Eds.), Affect, cognition, and stereotyping: Interactive processes in group perception (pp. 111-136). Academic Press.

Sullivan, A. L., \& Simonson, G. R. (2016). A systematic review of school-based social-emotional interventions for refugee and war-traumatized youth. Review of Educational Research, 86(2), 503-530.

Tercan, M., Bisagno, E., Cocco, V. M., Kaçmaz, T., Turnuklu, A., Stathi, S., \& Vezzali, L. (2020). Reducing prejudice toward Syrian refugee children: A vicarious contact intervention among Turkish elementary school children. Journal of Community Psychology, 49(2), 564-587.

Turner, R. N., \& Brown, R. (2008). Improving children's attitudes toward refugees: An evaluation of a school-based multicultural curriculum and an anti-racist intervention. Journal of Applied Social Psychology, 38(5), 1295-1328.

UNHCR. (2002). Refugees by numbers. Retrieved April 4, 2020 from http://www.unhcr.ch

Ulukütük, M. (2017). Suriyeli Muhacirlere Sosyal Uyum Rehberi (p. 58). BEKAM.

Vassilopoulos, S. P., Brouzos, A., Kasapogloua, E., \& Nikolopoulou, O. (2020). Promoting positive attitudes toward refugees: A prejudice-reduction, classroom-based group intervention for preadolescents in Greece. The Journal for Specialists in Group Work, 45(4), 292-306.

Vrij, A., Akehurst, L., \& Smith, B. (2003). Reducing ethnic prejudice: An evaluation of seven recommended principles for incorporation in public campaigns. Journal of Community and Applied Social Psychology, 13, 284-299.

Walker, H. (1989). Towards anti-racist, multicultural practice with under-fives. Early Child Development and Care, 41, 103-112.

Walker, I., \& Crogan, M. (1998). Academic performance, prejudice, and the jigsaw classroom: New pieces to the puzzle. Journal of Community and Applied Social Psychology, 8, 381-393.

Yıldırımalp, S., İslamoğlu, E., \& İyem, C. (2017). Suriyeli sı ̆̆ınmacıların toplumsal kabul ve uyum sürecine ilişkin bir araştırma. Bilgi Sosyal Bilimler Dergisi, 35, 107-126.

Publisher's Note Springer Nature remains neutral with regard to jurisdictional claims in published maps and institutional affiliations. 